\title{
A Greenhouse Screening Protocol for Fusarium Root Rot in Bean
}

\author{
Kristin A. Schneider ${ }^{1}$ and James D. Kelly ${ }^{2}$ \\ Crop and Soil Sciences Department, Michigan State University, East Lansing, \\ MI 48824
}

Additional index words. Phaseolus vulgaris, common bean, genetic resistance, Fusarium solani f.sp. phaseoli

\begin{abstract}
Root rot, caused by Fusarium solani f.sp. phaseoli, is a serious disease of bean for which successful control has been elusive. Genetic resistance to the pathogen is considered quantitative and is strongly influenced by environmental factors. To reduce environmental variation and facilitate selection in earlier generations, an accurate, consistent, and nondestructive greenhouse screen was developed for the evaluation of Fusarium root rot resistance in bean. We describe a protocol that involves the germination of seedlings in perlite, inoculation of roots and hypocotyls 10 days after planting and evaluation within 4 weeks. The accuracy of this greenhouse screen was confirmed by demonstrating significant correlations between greenhouse and field ratings. Two experiments that included 24 and 21 diverse bean genotypes, respectively, were performed in the greenhouse and the ratings were correlated with field ratings over two growing seasons. Correlation coefficients between the greenhouse and field ratings were significant and as high as 0.99 . Numerous genotypes can be evaluated within a short time for relatively minimal costs and labor. Furthermore, once roots have been rated and dipped in fungicide, plants can be transplanted for production of seed. This simple, rapid, and inexpensive protocol reduces environmental variation inherent to field ratings, thereby more accurately representing physiological resistance while maintaining a close association with observed field ratings.
\end{abstract}

Fusarium root rot, caused by the soilborne fungal pathogen Fusarium solani f.sp. phaseoli (Burk.) Snyd. \& Hans., has been reported to reduce bean yield in California, Colorado, Wisconsin, Washington, Nebraska, North Dakota, New York, Minnesota, and Michigan (Burke and Hall, 1991; Burke and Silbernagel, 1965; Estevez de Jensen et al., 1998; Keenan et al., 1974; Saettler and Anderson, 1978; Sippell and Hall, 1982; Smith and Houston, 1960; Steadman et al., 1975). The pathogen invades underground roots and stems directly through the epidermis, stomates and wounds (Christou and Snyder, 1962). Infection results in characteristic red streaks along the base of the hypocotyl, and discoloration and deterioration of the main taproot and laterals. Severely diseased roots cannot sustain growth and development of the above-ground plant, resulting in visible symptoms such as chlorosis, defoliation and stunting (Abawi and Pastor Corrales, 1990). Fusarium root rot is a

Received for publication 2 Dec. 1999. Accepted for publication 24. Mar. 2000. We recognize the assistance of L.P. Hart for the initial isolation of the pathogen used in this study. This research was supported by grant DAN 1310-G-SS-6008-00, and the U.S. Dept. of Agriculture National Needs Fellowship program. The cost of this paper was defrayed in part by the payment of page charges. Under postal regulations, this paper therefore must be hereby marked advertisement solely to indicate this fact.

${ }^{1}$ Current address: Holden's Foundation Seeds, P.O. Box 839, Williamsburg, IA 52361.

${ }^{2}$ Professor. To whom reprint requests should be addressed. E-mail address: kellyj@msu.edu particular problem in dark red kidney beans due, in large part, to the lack of any degree of genetic tolerance to this pathogen. Compounding this problem, stresses such as soil compaction and drought conditions, aggravated by the sandy soils on which this bean class is produced, inhibit root growth and vigor and may ultimately lead to increased susceptibility to disease.

Genetic resistance to F.sp. f.sp. phaseoli exists in P. vulgaris and root rot-resistant genotypes have been documented (Silbernagel, 1987; Wallace and Wilkinson, 1966). Progress toward improving root rot resistance, however, has been limited. Polygenic inheritance, compounded by strong environmental effects, has limited improvement of physiological disease resistance under field conditions (Beebe et al., 1981; Boomstra et al., 1977; Bravo et al., 1969; Hassan et al., 1971; Silbernagel, 1990; Smith and Houston, 1960; Tu and Park, 1993; Wallace and Wilkinson, 1965). Furthermore, evaluating roots is difficult and not amenable to large-scale population analysis. Many researchers examining Fusarium root rot resistance in bean have utilized greenhouse screening methods with variable results (Baggett and Frazier, 1959; Baggett et al., 1965; Beebe et al., 1981; Boomstra et al., 1977; Hassan et al., 1971; Tu and Park, 1993; Wallace and Wilkinson, 1965). In most cases, an association between greenhouse and field data was not established because a field trial with genotypes similar to those used in the greenhouse screen was not conducted. Soil medium, form and concentration of inoculum, hypocotyl vs. root ratings, number of ratings, labor, and cost must be considered in the development of a useful greenhouse screening method. Our objective was to develop a simple, controlled greenhouse screen to evaluate large numbers of bean genotypes for resistance to Fusarium root rot while eliminating environmental variation inherent in field experiments. The screening method presented will ultimately be valuable in the identification and evaluation of physiological resistance mechanisms present in bean.

\section{Materials and Methods}

Isolation and preparation of inoculum. Fusarium solani was isolated from kidney bean plants collected from production fields in Presque Isle County, Mich. Roots infected with F.sp. f.sp. phaseoli sampled from these fields were stored at $4{ }^{\circ} \mathrm{C}$ until isolation. Stem and root sections were bisected longitudinally and then cut into $0.5-\mathrm{cm}$ pieces. Segments from each plant were wrapped in cheesecloth and soaked under running deionized water for $24 \mathrm{~h}$. Stem sections were then surface sterilized in $95 \%$ ethanol, soaked in $10 \%$ Clorox $^{\circledR}$ for $5 \mathrm{~min}$, and dried on a paper towel moistened with $10 \%$ Clorox $^{\circledR}$. Sections were placed in a petri dish containing water agar (15 $\mathrm{g}$ agar in $1 \mathrm{~L}$ of water) and left under continuous light. Four to $5 \mathrm{~d}$ later, mycelia emanating from plant sections were removed at the growing point and transferred to potato dextrose agar (PDA) medium containing $100 \mathrm{mg} \cdot \mathrm{L}^{-1}$ ampicillin. These isolates were grown at room temperature under continuous light for 4 to 5 $\mathrm{d}$ and then replated on fresh PDA plus ampicillin. Ten milliliters of distilled water were added to spore cultures after 4 to $5 \mathrm{~d}$ of growth, and mycelia and conidia were scraped into solution for storage. Two milliliters of this solution was then added to a 20 -mL screw cap test tube with $3 \mathrm{~mL}$ of sterilized potting soil. The test tubes were held under continuous light for 4 to $5 \mathrm{~d}$ and then transferred to the refrigerator. One milliliter of this inoculum was grown on PDA plus ampicillin plates as needed. Isolates were characterized by conidial shape, blue spore color on PDA, and pathogenicity on bean (Burke and Hall, 1991). Continued culture of the fungus and verification of pathogenicity was performed by inoculating several plants with the specific isolate and reisolating the fungus using the above procedure.

Greenhouse screen. Several greenhouse screening tests were attempted and the following protocol was adopted. Using perlite-filled, 72-well greenhouse flats, a single seed was germinated in each well, using three to six seedlings per cultivar per replication. The perlite was saturated with half-strength Hoagland's solution at planting and flats were fertilized once every week thereafter with the same solution. Ten days after planting, $10 \mathrm{~mL}$ of a $2 \times 10^{5}$ spore suspension of F.sp. f.sp. phaseoli macroconidia was applied over the base of the hypocotyl using a 4-L hand pump sprayer. Inoculum was prepared by scraping PDA plates of $F$.sp. f.sp. phaseoli macroconidia into distilled water quantifying with a hemocy- 
tometer, and adjusting to the proper spore concentration. The Hawks 2 b isolate of F.sp. f.sp. phaseoli was used for all inoculations. Fourteen days after inoculation, seedlings were removed from flats, cleaned of excess Perlite and rated on a scale from 1 to 7 (Table 1). When seed was desired from inoculated seedlings, roots were dipped in a fungicidal solution of benomyl and transplanted to Bacto potting soil (Michigan Peat Co., Houston).

The aforementioned greenhouse screen was used to evaluate two groups of bean genotypes differing in genetic background. The first experiment (GH96) included 24 cultivars and advanced breeding lines, some of which were previously reported as possessing good levels of resistance to Fusarium root rot. The 24 genotypes were replicated four times and three plants were sown per replication (Table 2). The second greenhouse evaluation (GH97) consisted of 21 of the most popular Michigan-grown bean cultivars and advanced breeding lines. Six of the seven commercial market classes (except cranberry) were represented in this experiment (Table 3). Greenhouse evaluation was similar to that used in GH96 and consisted of four replications with three plants per replication. GH97 was repeated three times (Sept. 1997, Feb. 1998, and Dec. 1998) to verify reproducibility of this greenhouse screening protocol.

Field trials. Field trials were conducted on a Grace very fine sandy loam soil (coarsesilty, mixed, frigid, Typic, Hapludulfs) in Presque Isle County, Mich., where previous $F$. solani f.sp. phaseoli infections had been reported and from where the Hawks $2 b$ isolate was collected. The first field trial was conducted in 1996 and included the same 24 cultivars and advanced breeding lines described in GH96 (Table 2). Two-row plots, $7.6 \mathrm{~m}$ long, were hand planted on 17 June 1996 and replicated four times. Between-row spacing was $0.76 \mathrm{~m}$. Two weeks after planting, plots were thinned to 13 plants $/ \mathrm{m}$. Plots were arranged in a randomized complete-block design with four replications. Weeds were controlled chemically and manually. Twice during the growing season at pod fill (51 and $70 \mathrm{~d}$ after planting (DAP)), five random plants from each plot were carefully removed from the soil using a shovel and rated for Fusarium root rot symptoms using the root rating scale described in Table 1. Yield was recorded on a total harvestable area of $10 \mathrm{~m}^{2}$ per plot. Seed moisture samples were also taken for each plot and yields were adjusted to $18 \%$ moisture (Table 2). Field root rot evaluations were averaged over the two ratings for each genotype to provide an average score.

A second field trial consisting of the same 21 cultivars and advanced breeding lines described for GH97 was conducted in 1997 on the same field in Presque Isle County, Mich. A randomized complete-block design experiment with three replications was planted on 13 June 1997 with plot area and design similar to those used in 1996. Weeds were controlled manually. Plots were rated twice during pod fill, 52 and $86 \mathrm{DAP}$, and the scoring procedure was identical with that used in 1996.

Table 1. Description of disease rating scale used for all root rot experiments.

\begin{tabular}{|c|c|}
\hline Score & Phenotypic description \\
\hline 1 & $\begin{array}{l}\text { Healthy root system with no discoloration of root or hypocotyl tissue and no reduction in root } \\
\text { mass, compared to the uninoculated control. }\end{array}$ \\
\hline 2 & $\begin{array}{l}\text { Appearance of small reddish-brown lesions, } 0.1-0.2 \mathrm{~cm} \text { in length, at base of hypocotyl with size } \\
\text { and appearance of root mass normal. }\end{array}$ \\
\hline 3 & $\begin{array}{l}\text { Increase in intensity and size and coalescing of localized root/hypocotyl lesion circling } \approx 180^{\circ} \\
\text { of stem with lesions from } 0.5-1 \mathrm{~cm} \text { and } 10 \% \text { to } 20 \% \text { discoloration on roots but no reduction } \\
\text { in size of root mass. }\end{array}$ \\
\hline 4 & $\begin{array}{l}\text { Increasing intensity of discoloration and size of hypocotyl lesions with lesions becoming } \\
\text { extended and completely encircling the stem; } 5 \% \text { to } 10 \% \text { reduction in root mass with } 95 \% \text { of } \\
\text { roots discolored. }\end{array}$ \\
\hline 5 & $\begin{array}{l}\text { Increasingly discolored and extended hypocotyl lesions. } 100 \% \text { of roots intensely reddish-brown } \\
\text { with a } 20 \% \text { to } 50 \% \text { reduction in root mass. }\end{array}$ \\
\hline 6 & $\begin{array}{l}\text { Hypocotyl lesions encircling stem become more extended }(2 \mathrm{~cm}) \text {; root mass is intensely } \\
\text { discolored and reduced from } 50 \% \text { to } 80 \% \text {. }\end{array}$ \\
\hline 7 & $\begin{array}{l}\text { Pithy or hollow hypocotyl with very extended lesions. Root mass is reduced from } 80 \% \text { to } 100 \% \\
\text { and is functionally dead. }\end{array}$ \\
\hline
\end{tabular}

Table 2. Genotype, seed type, greenhouse rating (GH96), first (RRR1) and second (RRR2) field ratings, average field root rot ratings (AVG), seed yield, and 100-seed weight (SW) for 24 genotypes grown in Presque Isle County, Mich. in 1996.

\begin{tabular}{|c|c|c|c|c|c|c|c|}
\hline \multirow[b]{2}{*}{ Genotype } & \multirow[b]{2}{*}{ Seed type ${ }^{z}$} & \multirow[b]{2}{*}{ GH96 } & \multicolumn{5}{|c|}{ Field } \\
\hline & & & $\mathrm{RRR}^{\mathrm{y}}$ & RRR2 & AVG & Yield $\left(\mathrm{kg} \cdot \mathrm{ha}^{-1}\right)^{\mathrm{x}}$ & SW (g) \\
\hline B95219 & Black & 1.9 & 2.3 & 2.1 & 2.2 & 774 & 19.3 \\
\hline N203 & Black & 2.0 & 1.4 & 1.2 & 1.3 & - & - \\
\hline Newport ${ }^{w}$ & Navy & 2.2 & 2.8 & 2.8 & 2.8 & 1002 & 17.1 \\
\hline Huron ${ }^{w}$ & Navy & 2.3 & 1.9 & 1.7 & 1.8 & 1573 & 24.6 \\
\hline T39" & Black & 2.4 & 2.0 & 1.7 & 1.8 & 920 & 19.3 \\
\hline FR266 & Snap & 2.5 & 1.2 & 1.5 & 1.3 & - & - \\
\hline $\mathrm{A} 300^{\mathrm{w}}$ & Cream & 2.5 & 1.7 & 1.7 & 1.7 & 823 & 19.2 \\
\hline N94080w & Navy & 2.5 & 2.3 & 2.1 & 2.2 & 1137 & 18.8 \\
\hline NW590 & Pinto & 2.6 & 2.4 & 2.3 & 2.4 & 699 & 28.7 \\
\hline Seafarer & Navy & 2.6 & 2.4 & 2.4 & 2.4 & 1075 & 19.9 \\
\hline Sierra & Pinto & 2.7 & 1.9 & 2.1 & 2.0 & 827 & 32.1 \\
\hline Mackinac ${ }^{\mathrm{w}}$ & Navy & 2.8 & 2.7 & 2.9 & 2.8 & 955 & 20.2 \\
\hline Roza & Pink & 2.9 & 2.8 & 2.3 & 2.5 & 1165 & 31.7 \\
\hline UI-114 & Pinto & 3.0 & 2.1 & 2.0 & 2.0 & 635 & 37.7 \\
\hline NW 63 & Small red & 3.0 & 2.1 & 2.6 & 2.3 & 1153 & 31.3 \\
\hline K93654 & LRK & 3.0 & 3.0 & 4.8 & 3.9 & 1605 & 59.8 \\
\hline Viva & Pink & 3.1 & 3.0 & 1.5 & 2.3 & 1134 & 28.0 \\
\hline Chinook $^{\mathrm{w}}$ & LRK & 3.4 & 2.8 & 4.3 & 3.5 & 1492 & 53.4 \\
\hline Red Hawk ${ }^{w}$ & DRK & 3.6 & 4.6 & 5.8 & 5.2 & 1807 & 52.5 \\
\hline K94515 & LRK & 3.9 & 4.0 & 5.1 & 4.6 & 1321 & 55.6 \\
\hline K94803 & WK & 4.1 & 3.7 & 5.4 & 4.5 & 1407 & 52.5 \\
\hline Chinook $2000^{\mathrm{w}}$ & LRK & 4.2 & 3.0 & 4.3 & 3.6 & 1502 & 54.1 \\
\hline Montcalmw & DRK & 4.5 & 3.1 & 4.7 & 3.9 & 1529 & 55.9 \\
\hline Isles $^{w}$ & DRK & $\underline{4.8}$ & 4.7 & $\underline{5.4}$ & $\underline{5.0}$ & $\underline{1428}$ & $\underline{62.6}$ \\
\hline Mean & & 3.0 & 2.6 & 3.0 & 2.8 & 1182 & 36.4 \\
\hline $\operatorname{LSD}_{0.05}$ & & 0.9 & 1.0 & 0.9 & --- & 446 & 3.5 \\
\hline $\mathrm{CV}(\%)$ & & 17.0 & 27.4 & 20.3 & --- & 26.3 & 6.7 \\
\hline
\end{tabular}

${ }^{2}$ LRK, DRK, and WK signify light red kidney, dark red kidney, and white kidney seed types, respectively. ${ }^{y} \mathrm{RRR} 1$ and RRR2 are the root rot ratings taken 51 and $70 \mathrm{~d}$ after planting, respectively.

'Yield data are available for the genotypes marked with a "--", which failed to mature because of problems with adaptation.

${ }^{\text {w}}$ Common genotypes in 1996 and 1997 selected for correlation coefficients presented in Table 5.

Statistical analysis. Analyses of variance for all experiments were performed using the GLM procedure of SAS (SAS Institute, 1994). Pearson rank correlation coefficients between all ratings and yield data were calculated using the PROC CORR procedure of SAS.

\section{Results}

Significant genetic variation for root rot ratings was observed for all greenhouse and field experiments conducted, and for yield and 100 -seed weight in both field trials. Root rot ratings ranged from 1.9 to 4.8 with a mean of 3.0 in greenhouse experiments (Table 2); the black bean breeding line B95219 had the lowest rating, followed by $\mathrm{N} 203$, a traditional source of resistance (Wallace and Wilkinson, 1966). The large-seeded genotype FR266, which derives its resistance from N203 (Silbernagel, 1987), had one of the lowest root rot rating in the field but ranked higher in greenhouse experiments. Black bean genotypes tended to be the most resistant, followed by navy beans. Pinto and pink-seeded genotypes scored moderately well (2.6 to 3.1), and the most susceptible types were the largeseeded white, dark, and light red kidneys. 'Isles' and 'Montcalm', both dark red kidney beans, had the highest rating. 
Table 3. Genotype, seed type, greenhouse rating (GH97), first (RRR1) and second (RRR2) field ratings, and average field root rot ratings (AVG), seed yield, and 100-seed weight (SW) for 21 genotypes grown in Presque Isle County, Mich., in 1997.

\begin{tabular}{|c|c|c|c|c|c|c|c|}
\hline \multirow[b]{2}{*}{ Genotype } & \multirow[b]{2}{*}{ Seed type ${ }^{z}$} & \multirow[b]{2}{*}{ GH97 } & \multicolumn{5}{|c|}{ Field } \\
\hline & & & RRR1 $^{y}$ & RRR2 & AVG & Yield $\left(\mathrm{kg} \cdot \mathrm{ha}^{-1}\right)$ & SW (g) \\
\hline Avanti & Navy & 2.4 & 2.0 & 2.8 & 2.4 & 2410 & 19.0 \\
\hline Newport $^{\mathrm{x}}$ & Navy & 2.4 & 2.3 & 2.5 & 2.4 & 1849 & 19.3 \\
\hline T39 ${ }^{x}$ & Black & 2.4 & 2.6 & 2.4 & 2.5 & 953 & 18.0 \\
\hline $\mathrm{A} 300^{\mathrm{x}}$ & Cream & 2.5 & 2.5 & 2.4 & 2.5 & 2267 & 20.1 \\
\hline Phantom & Black & 2.5 & 2.9 & 2.2 & 2.5 & 1739 & 18.0 \\
\hline Mackinac $^{x}$ & Navy & 2.6 & 2.0 & 3.2 & 2.6 & 1740 & 19.1 \\
\hline N94080x & Navy & 2.6 & 2.7 & 2.6 & 2.6 & 1529 & 18.2 \\
\hline Mayflower & Navy & 2.8 & 3.2 & 2.4 & 2.8 & 1091 & 19.5 \\
\hline Vista & Navy & 2.9 & 2.7 & 3.0 & 2.9 & 1378 & 14.8 \\
\hline Alpine & GN & 3.2 & 2.9 & 3.5 & 3.2 & 997 & 29.5 \\
\hline Huron $^{x}$ & Navy & 3.3 & 2.8 & 3.7 & 3.3 & 1635 & 20.5 \\
\hline Kodiak & Pinto & 3.4 & 3.7 & 3.2 & 3.4 & 997 & 30.2 \\
\hline Matterhorn & GN & 3.7 & 3.1 & 4.3 & 3.7 & 791 & 30.1 \\
\hline K93629 & LRK & 4.1 & 3.8 & 4.5 & 4.2 & 740 & 55.8 \\
\hline Aztec & Pinto & 4.1 & 3.6 & 4.7 & 4.2 & 1153 & 33.7 \\
\hline Red Hawk ${ }^{\mathrm{x}}$ & DRK & 4.4 & 4.1 & 4.6 & 4.4 & 1565 & 55.1 \\
\hline Chinook $2000^{x}$ & LRK & 4.5 & 3.8 & 5.1 & 4.5 & 1717 & 54.4 \\
\hline Isles $^{\mathrm{x}}$ & DRK & 4.5 & 4.1 & 4.9 & 4.5 & 638 & 61.8 \\
\hline K93613 & LRK & 4.7 & 4.0 & 5.3 & 4.7 & 1797 & 63.7 \\
\hline Chinook $^{\mathrm{x}}$ & LRK & 5.0 & 4.5 & 5.5 & 5.0 & 493 & 47.0 \\
\hline Montcalm $^{\mathrm{x}}$ & DRK & $\underline{5.1}$ & $\underline{4.6}$ & $\underline{5.5}$ & $\underline{5.1}$ & $\underline{1279}$ & $\underline{52.0}$ \\
\hline Mean & & 3.5 & 3.2 & 3.7 & 3.5 & 1369 & 33.2 \\
\hline $\mathrm{LSD}_{0.05}$ & & 0.8 & 1.3 & 1.1 & --- & 873 & 2.2 \\
\hline $\mathrm{CV}(\%)$ & & 14.5 & 24.3 & 17.9 & --- & 30.5 & 3.2 \\
\hline
\end{tabular}

${ }^{\mathrm{z}} \mathrm{GN}, \mathrm{LRK}$, and DRK signify great northern, light red kidney, and dark red kidney seed types, respectively. yRRR1 and RRR2 are the root rot ratings taken 52 and $86 \mathrm{~d}$ after planting, respectively.

${ }^{x}$ Common genotypes in 1996 and 1997 selected for correlation coefficients presented in Table 5.

Table 4. Pearson rank correlation coefficients for yield, 100-seed weight (SW), first (RRR1) and second field (RRR2) root rot ratings, average field root rot rating (AVG), and greenhouse (GH) evaluations for each group of genotypes (GH96 and GH97). GH96 values are presented in the upper right-hand diagonal, whereas the GH97 values are printed in the lower left-hand diagonal.

\begin{tabular}{lllllll}
\hline & Yield & SW & RRR1 & RRR2 & AVG & GH96 \\
\hline Yield & & $0.69^{* * *}$ & $0.63^{* * *}$ & $0.74^{* * * *}$ & $0.72^{* * * *}$ & $0.61^{* * *}$ \\
SW & -0.33 & & $0.72^{* * *}$ & $0.89^{* * *}$ & $0.85^{* * *}$ & $0.87^{* * *}$ \\
RRR1 & -0.38 & $0.86^{* *}$ & & $0.87^{* * *}$ & $0.95^{* * *}$ & $0.77^{* * *}$ \\
RRR2 & $-0.54^{* *}$ & $0.87^{* * *}$ & $0.84^{* * *}$ & & $0.98^{* * *}$ & $0.83^{* * *}$ \\
AVG & $-0.47^{*}$ & $0.91^{* * *}$ & $0.94^{* * *}$ & $0.97^{* * *}$ & & $0.73^{* * *}$ \\
GH97 & $-0.46^{*}$ & $0.91^{* * *}$ & $0.94^{* *}$ & $0.97^{* * *}$ & $0.99^{* *}$ & \\
\hline
\end{tabular}

*,**,*** Significant at $P=0.05,0.01$, or 0.001 , respectively.

Root rot ratings from field trials confirmed the greenhouse data, and were positively and significantly correlated with greenhouse ratings $(r=0.73$; Table 4$)$. Field ratings ranged from 1.3 to 5.2 with a mean of 2.8 (Table 2 ). The dark and light red kidney genotypes tended to score the highest for root rot but also tended to be the highest yielding. 'Red Hawk', a new dark red kidney cultivar released from Michigan State Univ., was the highest yielding genotype but also had the highest root rot score followed by 'Isles'. N203 and FR266 were the most resistant genotypes in this trial. B95219, which was the most resistant genotype in GH96, was the most susceptible black bean genotype in the field trials, with a rating of 2.2. Black bean genotypes, however, remained the most resistant followed by pinto and navy seed types. Dark red kidney genotypes scored, on average, from 3.9 to 5.2 and light red kidneys scored from 3.5 to 4.6. Mean root rot scores based on field evaluations were 2.6 and 3.0 for the first (RRR1) and second (RRR2) evaluations, respectively, and ratings were positively and significantly corre- lated ( $r=0.87^{* * *}$, Table 4) among replicates.

The coefficients of variation (Cv) were moderate to high for yield and field root rot ratings, while the CV was lower for the greenhouse evaluation. Yields for the 1996 cultivar trial ranged from 635 to $1807 \mathrm{~kg} \cdot \mathrm{ha}^{-1}$ with a mean of $1182 \mathrm{~kg} \cdot \mathrm{ha}^{-1}$ (Table 2). The two sources of resistance (N203 and FR266) did not produce seed because of a lack of adaptation. Yield data were difficult to interpret for this trial because many genotypes were not adapted to this northern environment. Yield was positively and significantly correlated with field and greenhouse root rot ratings and was significantly correlated with seed weight (Table 4). The highest yielding genotypes were the highly susceptible, regionally adapted, large-seeded kidney types. The tendency for certain market classes to cluster for root rot ratings was reflected in a significant and positive correlation $\left(r=0.85^{* * *}\right)$ between seed size and average root rot score (Table 4).

Average ratings for $\mathrm{GH} 97$ ranged from 2.4 to 5.1 with a mean of 3.5 . Field ratings mirrored greenhouse ratings almost exactly
Table 5. Pearson rank correlation coefficients for root rot scores of 11 common genotypes evaluated in both greenhouse (GH96 and GH97) experiments. Correlation coefficients were calculated using both greenhouse and field ratings (1996, 1997).

\begin{tabular}{lcc}
\hline & 1997 Field & GH97 \\
\hline 1996 Field & $0.83^{* *}$ & $0.77^{* * *}$ \\
GH96 & $0.92^{\text {*** }}$ & $0.86^{* *}$ \\
\hline
\end{tabular}

*,**,**** Significant at $P=0.05,0.01$, or 0.001 , respectively.

( $r=0.99^{* * *}$; Table 4$)$, so subsequent results can be applied to either field or greenhouse experiments. The dark red kidney cultivar Montcalm, had the highest greenhouse rating, whereas 'Avanti' navy, 'Newport' navy, and 'T39' black bean exhibited the highest levels of resistance with scores of 2.4 (Table 3). Navy genotypes clustered as the most resistant market class along with black bean cultivars T39 and Phantom, in contrast with the highly susceptible kidney cultivars. 'Huron' was the only navy bean that scored above a 3.0 for this trial. Medium-sized pinto and great northern genotypes scored from 3.2 to 4.1 and kidneys scored from 4.1 to 5.1. The average score for field evaluations was 3.5 , similar to the mean in GH97 (3.5). The cv for GH97 was comparable to that observed in GH96. For both greenhouse experiments, CVs ranged from $3 \%$ to $10 \%$ less than cvs for field ratings (Tables 2 and 3 ). Repeatability was confirmed by significant and positive correlations among the data for three repeated greenhouse experiments (data not shown). Data for the Sept. 1997 screening was positively and significantly correlated with the Feb. 1998 and Dec. 1998 screenings $\left(r=0.70^{* * *}\right.$ and $0.81^{* * *}$, respectively). Data for the Feb. and Dec. 1998 screenings were also positively and significantly correlated $\left(r=0.87^{* * *}\right)$.

Yield for the 1997 field trial ranged from 493 to $2410 \mathrm{~kg} \cdot \mathrm{ha}^{-1}$ with a mean of 1369 $\mathrm{kg} \cdot \mathrm{ha}^{-1}$ (Table 3 ). Yields were calculated based on two replications because of extreme weed pressure in the third replication. Weeds were controlled manually but effective control was difficult since no herbicide was applied in 1997. 'Avanti' was the best yielding cultivar, as well as one of the most resistant genotypes in this trial. Contrary to the positive correlation observed between yield and GH96 root rot ratings in 1996, yield was negatively correlated with average root rot score in 1997 (Table 4). Seed size, however, was significantly and positively correlated with field and greenhouse root rot scores in 1997.

Pearson rank correlation coefficients $(r)$ for root rot ratings of 11 common genotypes grown in both GH96 and GH97 were also calculated based on the data in Tables 2 and 3. All values were significant at $P=0.05$ (Table 5).

\section{Discussion}

Our objectives were to develop a simple greenhouse screen to evaluate the reaction of lateral bean roots to inoculation with Fusarium root rot and correlate that response with field ratings. The current perlite-based greenhouse 
screen was inexpensive, required little maintenance, and permitted the evaluation of large populations, as 12 to 24 genotypes can be grown in one $54 \times 27 \times 6$-cm flat. Minimal requirements for greenhouse space ensure that large populations can be evaluated with limited resources. Time and labor constraints were also minimized since the time from planting to evaluation took 4 weeks and only daily watering and weekly fertilization were necessary. Using perlite, an inexpensive soil medium, roots could be cleared of adhering particles with relative ease so that ratings were not based on hypocotyl symptoms alone. Burke and Barker (1966) demonstrated that hypocotyl ratings are not adequate indicators of root rot damage. Using infested and noninfested islands of soil surrounding the hypocotyl and taproot, they found that severely diseased hypocotyls could support adequate plant growth and development. Our observations confirmed that lateral root damage was the more important contributor to yield reductions. The greenhouse screening presented in this paper provides a means to evaluate both hypocotyl and lateral root damage. The reddish discoloration typical of F.sp. f.sp. phaseoli infection in highly susceptible genotypes is striking and can be easily scored using the visual rating system for both hypocotyl and roots (Table 1).

Positive and highly significant correlations between greenhouse and field ratings for 11 bean genotypes common to both field trials, ensure confidence in this screening technique (Tables 4 and 5). These positive and significant relationships between the proposed greenhouse screening method and replicated field ratings prove that a controlled experiment can reflect field tolerance while reducing environmental variation and demands upon limited resources.

Reductions in environmental variation using this greenhouse screen are confirmed by a decrease in CVs between field and greenhouse evaluations. The CVs for GH96 and GH97 were from $3 \%$ to $10 \%$ less than those from the corresponding field evaluations (Tables 2 and 3). Coefficients of variation allow comparison of the variability of two experiments with different means by expressing the SD as a percentage of the mean. A decrease in CV can reflect an increase in mean value, a decrease in the SD, or both. Mean scores for field and greenhouse ratings were generally similar for both groups of genotypes. The lower $\mathrm{CV}$ values reflect reduced variability in greenhouse trials, thereby meeting our objective to develop a greenhouse screening method that would reduce the influence of environmental factors.

In addition to offering a more controlled screening environment for root rot, this protocol is nondestructive and allows for the testing of early generation material for which advanced generation seed is desired. Once rated, plants can be dipped in fungicide solution and transplanted. Considering the aforementioned criteria for a simple, consistent, accurate, inexpensive, nondestructive and rapid greenhouse screen to evaluate bean genotypes for Fusarium root rot resistance, the proposed protocol accurately and consistently satisfies these requirements.

\section{Literature Cited}

Abawi, G.S and M.A. Pastor-Corrales. 1990. Root rots of beans in Latin America and Africa: Diagnosis, research methodologies and management strategies. Centro Intl. Agri. Trop. (CIAT), Cali, Colombia.

Baggett, J.R. and W.A. Frazier. 1959. Disease resistance in the runner bean, Phaseolus coccineus L. Plant Dis. Rptr. 43:137-143.

Baggett, J.R., W.A. Frazier, and E.K. Vaughn. 1965. Tests of Phaseolus species for resistance to Fusarium root rot. Plant Dis. Rptr. 49:630633.

Beebe, S.E., F.A. Bliss, and H.F. Schwartz. 1981. Root rot resistance in common bean germ plasm of Latin American origin. Plant Dis. 65:485489.

Boomstra, A.G., F.A. Bliss, and S.E. Beebe 1977. New sources of Fusarium root rot resistance in Phaseolus vulgaris. J. Amer. Soc. Hort. Sci. 102:182-185.

Bravo, A., D.H. Wallace, and R.E. Wilkinson. 1969. Inheritance of resistance to Fusarium root rot of beans. Phytopathology 59:1930 1933.

Burke, D.W. and A.W. Barker. 1966. Importance of lateral roots in Fusarium root rot of beans.
Phytopathology 56:293-294.

Burke, D.W. and R. Hall. 1991. Fusarium root rot, p. 9-10. In: Compendium of bean diseases. $R$. Hall (ed.). APS Press, St. Paul, Minn.

Burke, D.W. and M.J. Silbernagel. 1965. Testing beans for field tolerance to Fusarium root rot. Phytopathology 55:1045-1046.

Christou, T. and W.C. Snyder. 1962. Penetration and host-parasite relationships of Fusarium solani f.sp. phaseoli in the bean plant. Phytopathology 52:219-226.

Estevez de Jensen, C., R. Meronuck, and J.A. Percich. 1998. Etiology and control of kidney bean root rot in Minnesota. Annu. Rpt. Bean Improv. Coop. 41:55-56.

Hassan, A.A., D.H. Wallace, and R.E. Wilkinson. 1971. Genetics and heritability of resistance to Fusarium solani f.sp. phaseoli in beans. J. Amer. Soc. Hort. Sci. 96:623-627.

Keenan, J.G., H.D. Moore, N. Oshima, and L.E. Jenkins. 1974. Effect of bean root rot on dryland pinto bean production in southwestern Colorado. Plant Dis. Rptr. 58:890-892.

Saettler, A.W. and A.L. Andersen. 1978. Bean diseases and their control, p. 172-179. In: L.S. Robertson and R.D. Frazier (eds.). Dry bean production-Principles and practice. Ext. Bul. E-1251, Michigan State Univ., East Lansing.

SAS Institute. 1994. The SAS system for Windows. Release 6.10. SAS Inst., Cary, N.C.

Silbernagel, M.J. 1987. Fusarium root rot-resistant snap bean breeding line FR266. HortScience 22:1337-1338.

Silbernagel, M.J. 1990. Genetic and cultural control of Fusarium root rot in bush snap beans. Plant Dis. 74:61-66.

Sippell, D.W. and R. Hall. 1982. Effects of pathogen species, inoculum concentration, temperature, and soil moisture on bean root rot and plant growth. Can. J. Plant Pathol. 4:1-7.

Smith, F.L. and B.R. Houston. 1960. Root rot resistance in common beans sought in plant breeding program. Calif. Agr. Sept., p. 8.

Steadman, J.R., E.D. Kerr, and R.F. Mumm. 1975 Root rot of bean in Nebraska: Primary pathogen and yield loss appraisal. Plant Dis. Rptr. 59:305-308.

Tu, J.C. and S.J. Park. 1993. Root-rot resistance in common bean. Can. J. Plant Sci. 73:365-367.

Wallace, D.H. and R.E. Wilkinson. 1965. Breeding for Fusarium root rot resistance in beans. Phytopathology 55:1227-1231.

Wallace, D.H. and R.E. Wilkinson. 1966. Origin of N203 (PI 203958). Annu. Rpt. Bean Improv. Coop. 9:38. 